CRITICAL REPORT

\title{
MORE ENABLING APPROACH: A CHALLENGE FOR THE PRACTITIONERS- A CRITICAL REVIEW
}

\begin{abstract}
The multidisciplinary teams of today are working in-collaboration and as one unit to assess, set goals, evaluate and provide reliable interventions to the patients/client. The essence of conceptual framework of ICF provides an opportunity to achieve the common goals of activity limitation and participation restriction by adapting a holistic model of rehabilitation encompassing the psychological, physical and the emotional needs with the advent of new techniques and modernized technologies.

The new enabling approach is challenge faced by the health care providers where patient preferences, empowerment and health related quality of life are most essential. The review will provide a critical analysis on the barriers faced by the practitioner especially during clinical decision making. Psychosocial perspectives of the client that is the most ignored area is also emphasized in the review and also motivational aspects of the patients in promoting the evidence based practice and clinical decision making and ultimately focusing on the enablement of the disabled.
\end{abstract}

\section{KEYWORDS}

Enabling Approach, Evidence Based Practice, HRQoL, Clinical Decision Making, Psychological, Disability, Activity Limitation, Participation Restriction
Amna Aamir Khan

Assistant Professor

Ziauddin College of Physical

Therapy

Ziauddin University

akhan39@caledonian.ac.uk

\section{Sumaira Imran Farooqui}

Associate Professor, Principal

Ziauddin College of Physical

Therapy

Ziauddin University

sumairaimranfarooqui@

gmail.com
[Khan AA, Farooqui SI. More enabling approach: a challenge for the practitioners- a critical review. Pak. j. rehabil. 


\section{INTRODUCTION}

With the advent of research, the professionals and multidisciplinary teams have modified the notion of rehabilitation from optimizing the function of the client physically to the consideration of psychosocial aspects of life ${ }^{1,2}$. The element of rehabilitation was re-presented by World Health Organization's International Classification of Functioning, Disability, and Health (ICF) where the health was stressed in terms of disability 3,4 . Several studies after 2007 were acknowledged for representing activity limitation and participation restriction especially for neurological diseases. Additionally, emphasis was laid s study on adapting a holistic model of rehabilitation encompassing the psychological, physical and the emotional needs of the disabled ${ }^{5,6}$.

Interestingly, the concept of disability was replaced from the medical model to the social model of disability where not only the impairments of the clients were dealt but the participation in the society was also considered ${ }^{7}$. The reason given by the professionals for adapting the medical model was due to the advent of new techniques and modernized technologies that have decreased the death rates ${ }^{8}$. Similarly, the increasing frequency and severity of the impairment due to the long term neurological disorder further raised the rate of disability 8,9 . These disabilities restricted the patients to participate in the mainstreams of social activities ${ }^{7}$ thus affecting empowerment. Therefore, empowerment is considered to be a capability to make decisions, providing opportunities to live with individuality ${ }^{10,11}$ where self-determination and independence are also considered ${ }^{12}$. The individuality achieved may enable the client in setting their own goals and creating new opportunities by removing the barriers to face the new environment ${ }^{13,14}$. Therefore a new concept emerged for the individuals with long term chronic disorders to restore the normal function, enabling and supporting to gain individuality and having control over them in the community ${ }^{15}$.

Both empowerment and enablement has been used simultaneously but empowerment is the process of providing the opportunity to the individual to take control where as enablement is supporting the individual to achieve the desired goal ${ }^{14}$. Although no universally agreed definition is being provided by the researcher for both enablement and empowerment but still are considered as multidimensional concepts with different individuals, communities and organizations providing different perspectives which is unique to every individual ${ }^{1,16}$. Stewart et al. in a study distinguished between the two, where empowerment provides feeling to the disabled to have the control over ones' self and work actively whereas enablement is about learning new skills, removing the barriers and exploring new areas ${ }^{14}$. However, empowerment and enablement both provides self-esteem, control over deci- sions and actions affecting the health as well as the opportunities to the disabled to master over the environmental factors ${ }^{17}$. Moreover, the emphasis was laid on the improvement of the physical, psychological and social aspects of life, where vocational training and activities of daily living were especially considered ${ }^{8,14}$. Furthermore importance was given on the uniqueness of the work provided by enablement with the improvement in function and generation of a feeling of control by the individual. A framework was required where the patients desired goals were placed as the most significant and an integral part also fulfilling the treatment criteria of the professionals ${ }^{18}$. Therefore, an enablement framework was put forward that may be considers as an ideal for the disabled where the requirements, role, abilities, coping strategies and desires of the may be considered as well as creating a relationship between client and patient ${ }^{19}$

The first frame work for planning, implementing and evaluating patient's education was presented by Stamleret al. $^{20}$ where the testing of the framework against several content areas was done to ensure that the frame-work may be used for multiple-contents. The goal of the patient was considered as an integral part of the framework. Moreover, the idea of enablement was clarified by determining the defining attribute, constructing model, related and contrary cases and identifying antecedents and consequences ${ }^{20,21}$. While reviewing the literatures in the fields of sociology, health, psychology and education different concepts were presented where the conflicts were recorded between the psychological and sociological literatures. However, sociological literatures provided more of the negative perspective of the enablement then the psychological literatures ${ }^{22}$. Furthermore, the researcher also pointed out two major aspects of enablement frame work: firstly, the framework had identified the goals desired by the client, components required to complete the goals (that is rehabilitation) and comparison of the needs (such as to become healthy). Secondly, the framework may be used to plan, implement and evaluate the effective education with respect to the patient desires ${ }^{22}$. However, it is vital for the patient and cares to receive appropriate information and education from the essential resources in order to be an 'informed patient'23,24 and to get involved in the decision-making. However the reliability and validity of the information achieved by the patients is still questionable ${ }^{25}$.

Furthermore, enablement framework may also be considered as a significant approach for the disabled where confidence to control and manage one's life at any situation is provided with the help of the health care professionals thus a step to become an 'expert patient'26. The notion of the expert patient has been recently emerged to modernize the health programs ${ }^{27}$ and to provide a better qual- 
ity of life 27,28 by linking the patients' ideas of empowerment ${ }^{26}$. Expert patients have confidence, information and skills to manage the disability by communicating with the professionals and developing the client-professional relationship. The expert patients are skilled with the communication and knowledge through the self-management/expert-program that are especially designed by the NHS for the long term and chronic neurological disorders especially stroke, multiple sclerosis, cerebral palsy ${ }^{26}$. Problem solving, decision making, resource utilization, discussion with the professionals and taking actions are the core skills taught to the expert patients during the self-management programs ${ }^{29}$. Moreover, self-management programs have been termed as a key towards the maintenance and improvement of health where patients' desires are of fundamental importance ${ }^{26}$. Even though the literature has revealed that the expert-management programs have played a fundamental role in reducing the admission during the emergency incidents, readmission to the hospital and re-hospitalization ${ }^{30}$ yet the major difficulty faced by the patient is the level of disability that can only be managed rather than being cured. Paradoxically, compliance and management of the health both are expected by the patient's expertise which may be suggested as a natural desire and a significant aspect of patient's life ${ }^{31}$. The studies conducted by the researchers ${ }^{23,31,32}$ previously have revealed the conflicts between the professionals and the expert patients due to the misinterpretation of the professional information by the patient and an insecurity of losing power by the practitioners $^{33}$.

However, a study conducted by Prof. Julie Barlow has shown that expert management programs has not only reduced the severity of symptoms but has also improved life satisfaction among the disabled ${ }^{30}$ since are aimed to enable the patient to achieve the goals by making them more active. Another report documented in King's Fund revealed that, $7 \%$ out of $9.1 \%$ people from the ethnic minority communities are at present using the expert-patient programs where participation depends on the extend of injury, age, social support and education $^{29}$. However, different responses of the individuals with respect to the psychosocial problems faced by the disabled individually but NHS is taking keen interest to deal the problems through the expert-management programs especially in the rural and deprived areas ${ }^{26}$.

Another study was conducted to test the enablement of the patient in the highly-deprived areas before and after the consultation by using the Patient Enablement Instrument $(P E I)^{34}$. The study assessed the impact of the encounter on the patient's ability to cope with and the understanding of the health problem by using a General Health Questionnaire GHQ-12 and the distress was also documented ${ }^{35,36}$. A comparison made between the most and least deprived areas resulted in a decreased enablement in the most deprived area. However, an increase in the psychosocial stress of the patient, long term illness and GP stress were also documented for the most deprived area. However a significant relationship was found between the severity of deprivement and professionals' empathy. The results also indicates a lower satisfaction rate of patient in the most deprived that is $\mathrm{GHQ}=$ $41.6 \%$ which was reduced to almost half in the least deprived area that is $28.1 \%$. Almost $30 \%$ of the patients wanted to discuss psychosocial problems whereas $65 \%$ documented more than one problem. However, the emphasis has been laid on considering the psychological and social conditions especially of the deprived area since these may lead to depression ${ }^{37}$.

Moreover, Hammell acknowledges majority of health care professionals while providing the interventions to improve the specific skills only focus on the targets to be achieved by the clients whereas neglecting the personal and psychosocial issues thereby unsatisfying the patients ${ }^{2}$. Although the prediction of the success of the treatment is directly depended on the patients' satisfaction still physiotherapist are reluctant to communicate and provide realistic information ${ }^{38}$. The barrier for the physiotherapist is the extent and the time of recovery and to meet expectations of patients and caregivers such as high recovery is expected by the patients suffering from stroke before being discharged. Wiles et al. reported the expectation of the recovery while interviewing 16 stroke patients and the physiotherapists in a longitudinal study ${ }^{39}$. Three sessions of interviews were taken to assess the deficits of movement, function and mood. However, the motor deficits improved in the $1^{\text {st }}$ and the $3^{\text {rd }}$ sessions still the over-optimistic behavior of the patients towards the recovery was not appreciated by the physiotherapist. Therefore, a special consideration should be given by the physiotherapist towards the communication strategies since verbal therapies may provide skills to the clients to replace activity limitation and social restriction with enablement and participation ${ }^{40,41}$ as well as living well with impairments ${ }^{42}$.

Physiotherapist aims to implement the standardized treatment protocols for every individuals during rehabilitation still the level of management differs with respect to the level of disability?. However, outcome major remains similar that is to maximize the participation of the client in the environment ${ }^{7}$ where the life situations are dealt with on the daily basis. For this reason, natural environment such as home, school and community may be considered as the most essential to increase the motor behavior especially for children suffering from $\mathrm{CP}^{7}$. Researchers have documented that the interventions should be implemented where activities occur daily espe- 
cially for the disabled children, since the motor learning skills may be established better when taken as a part of daily routine ${ }^{43}$ yet a number of studies neglected the environmental factors during the rehabilitation ${ }^{44}$. A study was conducted on 25 chronic stroke patients to examine the effectiveness of a four week dual-task exercise based program on the walking ability ${ }^{44}$. Results revealed a significant increase in the motor-task along with gait speed and cadence but the reliability of the study was questionable. Since, the increase in the gait speed and motor control were in the clinical setting where a controlled, predictable and uncluttered environment was present. On the other hand, a study conducted on 55 children suffering from mild to moderate spastic cerebral palsy, aged 2 to 7 years, receiving the functional physical therapy in the natural environment, improved the motor skill more than the improvement of the children abilities in the reference group as was measured on the Pediatric Evaluation of Disability Inventory (PEDI). Therefore environment may be considered essential to teach the individuality especially to the children suffering from $\mathrm{CP}^{7}$.

Moreover, in a review of papers Mihaylov et al, identified various environmental factors that influence participation of the disabled children. However, other various barriers such as inappropriate footwear, medication, dependence, noise and unavailability of space restricted the participation and freedom of the children in the study ${ }^{45}$. In addition, other significant factors that influence the level of participation of the child such as building the structure, loss of income and provision of equipment considered as essential for rehabilitation were not considered $^{32}$. Furthermore, the disabled child is depended directly or indirectly on the caregivers/parents hence the parental awareness should be provided by the physiotherapists parental neglection has been documented. Also, while setting the goals for the disabled the caregiver/parents and the client both perspectives should be given priorities by the physiotherapist ${ }^{46}$. However, the enabling approach may reduce the burden the parents/care givers of the disabled child as a significant time is spent by the care giver and the rate is still increasing day by day. However, caring and care giving is a complex activity requiring set of knowledge, skills and values and the practitioners may take account of the complexities especially faced by the parents of the disabled suffering from chronic childhood illness as a disruption in the sense of control is seen in the mother leading to a decrease in empowerment ${ }^{47}$. An appreciation of shared-decision has been recorded in the literature where exchange of information, deliberation about the treatment options and then implementation of the treatment has been a suggested as significant ${ }^{19}$. However, a rehabilitation program tailored according to the needs and requirement of the individual may improve the participation in the community ${ }^{19}$.
Mayo et al. interviewed 434 patients with $1^{\text {st }}$ ever stroke in the community with a follow up of 2 years to estimate the influence of stroke on the extent of activity, participation and quality of life $(\mathrm{QOL})^{37}$.A comparison was being made when 486 community-dwelling controls were interviewed by telephone. The researcher documented $90.6 / 100$ on the Barthel Index for the stroke group whereas $39 \%$ of patients had limitation in functional activities. In addition, 54\% reported limitations with higher-level activities of daily living where the housework and shopping, and $65 \%$ reported restrictions in participation in the community activities. Furthermore, the QOL reported to be 7 points lower than the controls on the SF-36 scale ${ }^{47}$. The researcher also indicated that almost $50 \%$ of the community-dwelling stroke population are unable to participate independently in the community since more than $70 \%$ had at least one difficulty in performing the activities of daily living (ADLs). As meaningful activity limitation along with boredom was also reported providing an indication of the worsening of the QOL which may be considered as the significant outcome measure in the clinical trials ${ }^{48}$. However, in another study a researcher after interviewing 28 families emphasized on the development of significant scale for the measurement of QOL for $\mathrm{CP}^{49}$.

Recently, the researchers are keener to explore the participation of the stroke patients more as may be considered as one of the most significant long term disorder that restricts the activities in the community. The evidence was presented in a study where the stroke patients documented to be among three most restricted disorders ${ }^{49}$. The comparison was made among 126 participants suffering from neuromuscular disease, rheumatoid arthritis, spinal cord injury, fibromyalgia on a recently developed questionnaire; Impact on Participation and Autonomy (IPA). More over emotional distress was found to be the most important contributing factor to the restriction faced by the participants. However, the major limitation of the study was the low response rate that may have directly affected the results and a lack of the controls may have induced a bias factor. However, multidimensional approaches such as the enabling approach may contribute to increase the QOL by decreasing the anxiety, depression and stress faced by the disabled.

Literature reports professionals as being an 'agent' where responsibility lies on the agent to provide the consumer (patient) the desired treatment ${ }^{50}$.

A new approach has been placed by the researchers known as evidence based patient-choice (EBPC) approach where evidence-informed choice and shared decision making are both appreciated $^{51}$. Therefore, the evidence based information is being provided to the patients in order to facilitate the abilities of the clients in making decisions. However, mutual respect, hones- 
ty, trust may be considered as significant to promote the EBPC as well as the communication skills in the physiotherapist. Although the researchers appreciates EBPC as an enabling approach to enhance the participation of the disabled yet more research is required to implement into practice ${ }^{52}$.

However, different modernized technologies are being used by the researcher to provide comfort and feasibility to the disabled hence to encourage in decision making and planning goals with the practitioners. However, telemedicine, has been a new approach towards enablement by empowering the patient to convey the desires to the health care professionals however telemedicine may be considered a way to generate a positive excitement and enthusiasm to participate in the community however, researchers reported a optimistic approach as patients often find video interviews less life threatening then face to face interviewing. Although, professional anxiety and discomfort has been reported. Also, Tele-consultants may be found to be at risk of privacy and assessment especially with the long term neurological disorders leading to dissatisfaction for the professional. Moreover, telemedicine may be inappropriate with the disabled children where environmental modification and adaptation may be considered as most significant to increase the participation in the community. However, appropriate footwear, lowering the bed, widening the doors to allow the wheel chair access and many other factors may contribute to increase the participation of the children in the community. However the participation may also be improved by reducing the cognitive skills ${ }^{44}$. Recently the development of novel assistive technologies devices such as Assistive Technology for Cognition (ATC) has shown remarkable results in improving the participation of the disabled by improving the functional activities such as visual, auditory and language. Moreover, ATC may assist the patients to work independently as well as help to return to work since disability is considered as a significant barrier to work. Moreover, dairies, calendars and pocket coaches may be used to enhance the participation as by providing independence to perform the activities of the daily living. However, the home-based rehabilitation programs may also be significant in provide optimal independence, teaching the problem-solving skills, building confidence and preparing for the life that is the external environment.

\section{CONCLUSION}

The more enabling approach may be a new beginning in the field of rehabilitation by enhancing participation, increasing power, individuality and confidence among the disabled. Physiotherapist and other health care professionals are aiming to restore the normal functions in the society, increasing the decision-making and providing greater satisfaction, despite of the persistent sequelae of illness, such as impairments and disabilities. However, NHS has played a vital role in promoting the enabling approach by providing the information through internet and even and recruiting the people to teach self-management program in the language as feasible to the patients. The information gained through internet, as eHealth programs are considered quickest, latest and the most appropriate information. Moreover, the information attained has enabled the patients to be self-esteemed and has increased the power of making decisions. Moreover, new and modernized strategies are used by the professionals such as telemedicine, modification of the external environment and ATC to promote the participation of the disabled in the society. Although a number of challenges may be faced by the health care professionals in maintaining the enabling approach especially in the rural and deprived area where the access to the services are limited (Mercer et al., 2007). Yet the practitioners may cope up with the barriers faced and especially by considering the psychosocial perspectives of the client and taking keen interest in promoting the EBPC and ultimately focusing on the enablement of the disabled.

\section{REFERENCES}

[1] Furze J. Describing the clinical reasoning process: application of a model of enablement to a pediatric case. Physiother Theo Prac. 2013;29(3):222-231

[2] Hammell KW. Perspectives on Disability \& Rehabilitation. Oxford: Churchill Livingstone; 2006

[3] Iemmi V, Kuper H, Blanchet K, Gibson L, Kumar K, Rath $S$, et al. Community-based rehabilitation for people with disabilities. IntInitiarlmpaEvalu. 2016

[4] D'Alisa S, Baudo S, Mauro A, Miscio G. How does stroke restrict participation in long term post stroke survivors? ActaNeurologicascandinavica. 2005;1 12:157-162

[5] Wade D. Rehabilitation-a new approach: part two: the underlying theories. ClinRehabil. 2015;29(12):1145-1154

[6] Wade DT, De Jong BA. Recent advances in rehabilitation. Bri Med J. 2000;320:1385-1388

[7] Goldstein DN, Cohn E, Coster W. Enhancing participation for children with disabilities: application of the ICF enablement framework to pediatric physical therapist practice. PediaPhysTher. 2004; 16(2):114-120

[8] Murray CJL, Vos T, Lozano R, Naghavi $M$, Flaxman AD, Michuad C, et al. Disability-adjusted life years (DALYs) for 291 diseases and injuries in 21 regions, 1990-2010: a systematic analysis for the global burden of disease study 2010 . 2012;380(9859):2197-2223

[9] Scottish Executive. Coordinated integrated and fit for purpose: a delivery framework for adult rehabilitation in Scotland. Edinburgh: Scottish 
Executive; 2007

[10] Peoples H, Satink T, Steultjens E. Stroke survivors' experiences of rehabilitation: a systematic review of qualitative studies. 2011;18(3):163-171

[11] Morris J. Care of empowerment? DisabliRighPersp J. 1997;31 (1):54

[12] Lobentanz IS, Asenbaum S, Vass K, Sauter C, Kollegger $\mathrm{H}$, Kristoferitsch $\mathrm{W}$, et al. Factors influencing quality of life in multiple sclerosis patients: disability, depressive mood, fatigue and sleep quality. ActaNeurologica Scand. 2004; 110:6-13

[13] Jackson D, Hodges C, Molesworth M, Scullion R (Eds.). Reframing disability: media, (dis)empowerment and voice in 2012 paralympic games. DisabilSocie. 2016;31 (2):291-293

[14] Stewart A. Empowerment and enablement: occupational therapy 2001. Bri J OccupTher. 1994;57(7):248-254

[15] Scottish Executive. Delivering care, enabling health. Edinburgh: Scottish Executive; 2006

[16] Little P, Everitt H, Williamson I, Warner $G$ et al. Observational study of effect of patient centredness and positive approach on outcomes of general practice consultations. Bri Med J. 2001;323(7318):908

[17] Maccoby M. Re-thinking empowerment. Res Tech Manag. 1999:42(5):56

[18] Stamler LL, Cole MM, Patrick LJ. Expanding the enablement framework and testing an evaluative instrument for diabetes patient education. J AdvNur. 2001;35(3):365-372

[19] Madden RH, Dune T, Lukersmith S. The relevance of the international classification of functioning, disability and health (ICF) in monitoring and evaluating community-based rehabilitation ( CBR). DisabilRehabil. 2014;36(10):826-837.

[20] Stamler LL. Toward a framework for patient education: an analysis of enablement. J Holist Nur. 1996; 14(4):332-347

[21] Mani S, Przybyla A, Good DC, HallandKYSainburg RL. Contralesional arm preference depends on hemisphere of damage and target location in unilateral stroke patients. NeurorehabNeura Rep. 2014;28(6):584-593

[22] Sivan M, Gallaghar J, Holt R, Weightman A, Levesley $M$, Bhakta B. Investigating the international classification of functioning, disability and health (ICF) framework to capture user needs in the concept stage of rehabilitation technology development. Assist Technol. 2014;26(3):164-173

[23] Henwood F, Wyatts S, Hart A, Smith J. 'Ignorance is bliss sometimes' constraints on the emergence of the 'informed patient' in the changing landscapes of health information. Socio Health III. 2003;25(6)589-607

[24] Tsai PC, Yip PK, Tai JJ, Loq MF. Needs of family caregivers of stroke patients: a longitudinal study of caregivers' perspectives. PatiePref Adhere. 2015;9:449-457

[25] Fox NJ, Ward KJ, O'Rourke AJ. The 'expert patient': empowerment or medical dominance? The case of weight loss, pharmaceutical drugs and the internet. SocSci Med. 2005;60(6):1299-1309

[26] Department of Health. Expert Patients Programme. [internet]. Available from: http://www.dh.gov.uk/en/Aboutus/MinistersandDe$\mathrm{p} \quad \mathrm{a} \quad \mathrm{r} \mathrm{m}$ e $\mathrm{n} \dagger \mathrm{L} \quad \mathrm{e}$ a $\mathrm{d}$ ers/ChiefMedicalOfficer/ProgressOnPolicy/Pro gressBrowsableDocument/DH_4102757

[27] Visse MM, Aben L, Heijenbrok-Kal $M H$, Busschbach JJV, Ribbers GM. The relative effect of coping strategy and depression on health-related quality of life in patients in the chronic phase after stroke. J Rehabil Med. 2014;46(6):514-519

[28] Donaldson L. Expert patients usher in a new era of opportunity for the NHS. Bri Med J. 2003;326:1279-1280

[29] Corben S, Rosen R. Self-management for long-term conditions, patients perspectives on the way ahead. London: King's Fund; 2005.

[30] Bodenmann P, Veloaki VS, Ruggeri O, Hugli $O$, Burnand B, Wasserfallen JB, et al. Case management for frequent users of the emergency department: study protocol of a randomized controlled trial. Bio Med Cent. 2014; 14:264

[31] Zwerling C, Whitten PS, Sprince NL, Davis CS, Wallace RB, Blanck PD, Heeringa SG. Workforce participation by persons with disabilities: the national health interview survey disability supplement 1994 to 1995. J Occup Environ Med. 1994;44(4):358-364

[32] Ford S, Schofield T, Hope T. What are the ingredients for a successful evidence-based patient choice consultation? A qualitative study. Socisci Med. 2003;56(3):589-602

[33] Cott C. Client-centered rehabilitation: client perspectives. DisabilRehabil. 2004;26(24):1411

[34] Mercer SW. Fitzpatrick B, Glen G, Gaby V, McConnachiq A, Watt GCM. More time for complex consultations in a high deprivation practice is associated with increased patient enablement. Bri J Gen Prac. 2007:57(545):960-966

[35] Lopez PS, Roman AISS, Dresch V, Garcia-Quintans L, Rodrigo-Holgado I. Women are more at risk of poor mental health: mental health of Spanish nurses measured by the GHQ-12. Wome Health Bulle. 2016;3(2):1-5

[36] Glozah FN. Factor structure and psychometric properties of the general health questionnaire (GHQ-12) among Ghanaian adolescents. J Child Adol Men Health. 2015;27(1):53-57

[37] Mayo N, Wood-Dauphinee S, Cote R, Durcan L, Carlton J. Activity participation and quality of life 6 months post stroke. Arch Phys Med Rehabil. 2002;83:1035-1042

[38] Parry RH. Official recommendations and actual practice in physiotherapy: managing troubles of physical performance. Comm Med. 2005;2(2):151-161 
[39] Wiles R, Ashburn A, Payne S, Murphy C. Patients" expectations of recovery following stroke: a quality study. DisabilRehabil. 2002;24(16):841-850

[40] Royal College of Speech and Language Therapist. Moving from care to enablement [internet]. Available from: http://www.rcslt.org/government/scotland_rehabilitation_response.pdf

[41] Trieschmann R. Spinal cord injuries-psychological, social and vocational rehabilitation. 2nded. New York: Demos; 1988

[42] Rowles $G$. The meaning of place as a component of self. In: Crepeau E, Schell B (Eds.). Williard and Spackmans occupation therapy. Philadelphia: Lippincott Williams \& Wilkins; 2003

[43] Yang YR, Wang $Y$, Chen Y, Kao M. Dual-task exercise improves walking abilityin chronic stroke: a randomized controlled trial. Arch Phys Med Rehabil. 2007;88(10):1236-1240

[44] Mihaylov SI, Jarvis SN, Colver AF, Beresford B. Identification and description of environmental factors that influence participation of children with cerebral palsy. Dev Med Child Nero. 2004:46(5):299-304

[45] Hale LA, Piggot J. Exploring the content of physiotherapeutic home-based stroke rehabilitation in New Zealand. Arch Phys Med Rehabil. 2005:86(10):1933-1340

[46] Gibson $\mathrm{CH}$. The process of empowerment in mothers of chronically ill children. J AdvNur.
1995;21(6):1201-1210

[47] Kielbergerova L, Mayer Jr A, Vanek J, Bruthans J, Wohlfahrt P, Cifkova R. Quality of life predictors in chronic stable post-stroke patients and prognostic value of SF-36 score as a morality surrogate. 2015;6(5):375-383

[48] Bjornson KF, McLaughlin JF. The measurement of health-related quality of life (HRQOL) in children with cerebral palsy. Eur J Neuro. 2001;8(Suppl 5):182-193

[49] Waters E, Maher E, Salmon L, Reddihough D, Boyd R. Development of a condition-specific measure of quality of life for children with cerebral palsy: empirical thematic data reported by parents and children. Child: Care, Health Dev. 2005;31 (2):127-135

[50] Salter K, Jutai JW, Teasell R, Foley NC, Bitensky J, Bayley M. Issues for selection of outcome measures in stroke rehabilitation: ICF participation. DisabilRehabil. 2005;27(9):507-528

[51] Gafni A, Charles C, Whelan T. The physician-patient encounter: the physician as aperfect agent for the patient versus the informed treatment decision-making model. SocSci Med. 1998;47(3):347-354

[52] Every-Palmer S, Howick J. How evidence-based medicine is failing due to biased trials and selective publication. J EvalClinPrac. 2014;20(6):908-914 